\title{
Designing near-natural planting patterns for plantation forests in China
}

\author{
Gongqiao Zhang ${ }^{1}$, Gangying Hui ${ }^{*}$, Yanbo Hu', Zhonghua Zhao', Xiuling Guan², Klaus von Gadow ${ }^{3}$ and \\ Ganggang Zhang ${ }^{1}$
}

\begin{abstract}
Background: China has a long tradition of managing planted forests. Different species of Populus, Eucalyptus, Larix, Cunninghamia and Pinus are planted to satisfy the local demand for wood products and provide ecological services at the same time. Evidence of the greater resilience of natural forests provides the motivation to develop asymmetric planting patterns, which is the focus of this study. We present a new method for designing plantation patterns that follow those observed in natural ecosystems and to maintain some regularity for operational convenience.

Methods: Based on the uniform angle index, we analyzed the spatial structure of six natural forests in different regions of China. The uniform angle index describes the degree of spatial uniformity of the $n$ nearest neighbors of a given reference tree. Accordingly, we identified all possible patterns of a neighborhood group within a regular planting pattern and developed a method to optimize planting point arrangements that contain some randomness as well as a minimum degree of regularity.

Results: (1) There are 13 types of structural units in a regular planting, including seven random units, five even units and one cluster unit; (2) Five near-natural arrangements are presented with a minimum proportion of 50\% of random units. These five arrangements represent a combination of regularity for operational convenience and asymmetry.

Conclusions: The new planting patterns developed in this study are expected to increase the asymmetric competition and resilience of these important ecosystems. Some experimental plantings, based on our findings, have already been established, e.g., in Pinus tabulaeformis plantations in Tianshui, Gansu Province, and in a Populus deltoides plantation in Fangshan near Beijing.
\end{abstract}

Keywords: Plantation, Near-natural forest, Uniform angle index, Forest spatial structure, Asymmetric competition

\section{Background}

Plantation forests or planted forests are cultivated forest ecosystems established by planting or seeding or both in the process of afforestation and reforestation (Helms 1998), typically consist of intensively managed, even aged, and regularly spaced stands of a single tree species, primarily for wood biomass production and provide ecological services at the same time, such as soil and water conservation or wind protection. Expansion of planted forests and intensification of their management has raised concerns among forest managers and the public over the implications of these trends for sustainable

\footnotetext{
* Correspondence: hui@caf.ac.cn

${ }^{1}$ Research Institution of Forestry, Chinese Academy of Forestry, Beijing 100091, China

Full list of author information is available at the end of the article
}

production and conservation. With more than 69 million hectares, China has the largest plantation area of any country in the world (Zeng et al. 2015), and has been committed to conserve and expand forests with the goal of mitigating land degradation, air pollution and climate change in recent decades (Chen et al. 2019). China has the most extensive area of plantation monocultures in the world as well, according to the last (8th) National Forest Inventory, the total area of productive plantation forests in China is $47,069,600$ ha. The five most important plantation species, which together comprise approximately $60 \%$ of this area, are listed in Table 1, including the associated planting espacements.

Much of the history of forest science and management in the last two centuries has focused on optimizing the efficiency of wood production, mostly for timber, pulp 
Table 1 The five most important plantation species and associated planting espacements in China

\begin{tabular}{|c|c|c|c|}
\hline Species & Planting espacement (m) & Area (ha) in China & References \\
\hline $\begin{array}{l}\text { Cunninghamia } \\
\text { lanceolata }\end{array}$ & $\begin{array}{l}2 \times 3,2 \times 1.5 \text { (middle and North of Fujian Province) } \\
\text { and } 2 \times 1,1 \times 1.5 \text { (South of Fujian Province); } 1.5 \times 2 \\
\text { (Sichuan Province) }\end{array}$ & $8,946,400$ & $\begin{array}{l}\text { Huang and Wu 1990 } \\
\text { Xiao et al. } 2010\end{array}$ \\
\hline $\begin{array}{l}\text { Populus } \\
\text { deltoides }\end{array}$ & $\begin{array}{l}4 \times 4 \text { (Yunnan province) } \\
2 \times 3,3 \times 3,3 \times 4,4 \times 4 \text { (other provinces) }\end{array}$ & $8,538,300$ & $\begin{array}{l}\text { Ma et al. 2015; } \\
\text { Sheng } 2014\end{array}$ \\
\hline Eucalyptus & $\begin{array}{l}2 \times 3 \text { (Euc. grandis } \times \text { Euc. urophylla Guanglin No. 9; Guangxi Province) } \\
2 \times 3,2 \times 3.5,1.5 \times 3 \text { (Eucalyptus clones: DH32-26, DH32-28, DH32-29, } \\
\text { GL-UG9, Guangxi Province) }\end{array}$ & $4,455,200$ & $\begin{array}{l}\text { Zhu 2014; } \\
\text { Chen et al. 2014; }\end{array}$ \\
\hline Larix & $2 \times 3 ; 3 \times 3$ & $3,136,900$ & Sheng 2014 \\
\hline $\begin{array}{l}\text { Pinus } \\
\text { massoniana }\end{array}$ & $3 \times 3,4 \times 4$ & $3,062,100$ & Sheng 2014 \\
\hline Total area & & $28,138,913$ & \\
\hline
\end{tabular}

and fuel (Carnus et al. 2006). This focus is based on the notion that homogenous products are cheaper to produce and manipulate (Puettmann et al. 2015). The regular planting pattern may facilitate the planning and execution of planting activities and mechanized operations. These ideas are inherent in planting policies (Stiell 1978), without giving due consideration to the natural succession of plantation ecosystems. Resilience of a plantation ecosystem determines the extent and duration of ecological benefits. Ecological resilience, the ability of a system to absorb impacts before a threshold is reached where the system changes into a different state, describes the tendency of a system to return to its equilibrium values after a disturbance (Redfearn and Pimm 1987), is greater in natural tree communities than in planted monocultures (Gunderson 2000). A resilient system is considered as adapted to the prevailing environmental circumstances, moderately fluctuating due to the incidence of disturbances, but not easily perturbed by stronger episodic natural events. They could be sustained on a moderate management regime and serious health problems are not expected, provided that environmental conditions remain unchanged (Führer 2000). The ability of forest ecosystems to persist, is based on their natural mechanisms for control or management of these forces. Efficiency of these mechanisms is the essence of development and resilience of ecosystems (Bormann and Likens 1979). Success of control or management of the destabilising forces, impinging on forest ecosystems, therefore determines the success or failure of forest management. Generally, silvicultural and site management practices in planted forests have direct impacts on stand dynamics and structure and will greatly influence whole forest ecosystem (Allen et al. 1995; Nys 1999). Intensity of site preparation, stand establishment, control of competing vegetation, pre-commercial or commercial thinning, pruning, methods, and timing of harvest largely determine the rate of stand development, the initiation and duration of stem exclusion and other stages of stand development, and changes in tree architecture and stand structure (Oliver and Larson 1996).

However, compared with natural forests, planted forest ecosystems is understood as the lack of intrinsic self-regulation (Führer 2000), and generally refers to lower species diversity (Hartley 2002), less resistant to insect pests (Jactel et al. 2005) and diseases (Pautasso et al. 2005) etc.. But improvement of species diversity in plantation forests remain a challenge due to economic and technological constraints at present. Thus, to increase spatial heterogeneity appropriately when plantations are established or tended breaks a new ground (O'Hara 1996; Hartley 2002). The rigid arrangement of planting points defines the spatial distribution of all trees for a given tree density and determines the direction and irradiation within the plantation community. The arrangement of planting points is usually regular, and the result of this pattern is that each tree has the same growing space, which is often assumed to be the most adequate use of the available forest area (Dunning 1923; Baker 1934; Toumey and Korstian 1947; Bella 1967). A symmetrical and orderly arrangement of planting points may be convenient for mechanized afforestation and stand tending. However, the uniform assignment of available resources and growing space results in an artificial pattern that differs from the patterns found in natural tree communities.

Natural succession contributes to the variations of forest distribution patterns and structural diversity in natural communities (He and Duncan 2000; Gonçalves and Batalha 2011). Forest structure, which refers to the specific spatial arrangement of trees and their individual attributes, especially tree species and tree size, has become the focus of numerous studies involving natural forest communities (Janzen 1970; Connell 1971; Hubbell 1979; Lieberman and Lieberman 1987; Condit et al. 2000; Hubbell et al. 2001). Structural diversity, particularly spatial structure, changes continuously as stand 
development proceeds and is particularly significant in plantation forests. Structural diversity can be as important for animal species diversity as the diversity of plant species in forest plant communities (Carnus et al. 2006). The structural complexity of the planted forest is an important determinant of subsequent biodiversity enrichment for near-natural management (Parrotta et al. 1997) . Forest spatial structure is the result of past dynamics and complex interactions among many processes acting on a stand (Moravie and Audrey 2003), including environmental heterogeneity (Valverde and Silvertown 1997), and competition among individuals and populations (Duncan 1991).

Forests also change dynamically as individual trees grow, die, and compete with one another for resources such as light, water and nutrients especially after the crown closure occurs. Therefore, tree competition and population dynamics may have a major effect on the energy, water and carbon balances between the atmosphere and forests (Toda et al. 2010). Competition for resources can be either symmetric or asymmetric. In natural communities, forest microenvironments are usually highly variable, resulting in asymmetric patterns of niche and competition, leading to the differentiation of individual trees over time. The degree of asymmetry can have profound consequences on the dynamics in vegetation stands (Weiner 1990; Weiner and Thomas 1986; Werger 2010). According to Yang (2001) symmetric competition does not provide system positive effect because equal competitors will not survive together. The development of a forest ecosystem requires asymmetric competition, which develops over long periods of time (Tang 2003; Huston and Smith 1987; Breugel 2007). Several authors have presented evidence that asymmetric competition of trees is one of the reasons for the resilience of unevenaged forests (Bartelink and Olsthoorn 1999; Tang 2003). Differences in micro site conditions affect the ability of individual plants to thrive in certain locations and to fail in others. Therefore, numerous authors have suggested that it is necessary to learn from natural ecosystems, especially regarding their structure and dynamics (Christensen and Emborg 1996; Shao 2003; Paquette and Messier 2010; Li et al. 2012, 2014; Liu et al. 2015; Yin 2015). Therefore, a new vision of forest management expresses itself in a set of several silvicultural principles and management (Jacobsen 2001; Schütz 2002; Mason et al. 2003; Schütz et al. 2012; Bauhus et al. 2013). One of these refers to the maintenance of structural diversity and small-scale variability, with varying management approaches across a range of spatial scales, and a special emphasis on the diversity of stand structures at small scales, including single-tree and neighborhood conditions. Such ecosystems show greater resilience with the capacity to return to the precondition state following a perturbation, including maintenance of their essential characteristics, taxonomic composition and structures, and ecosystem functions (Holling 1973; Liu et al. 2015).

\section{Objectives}

A given number of trees may be planted in random positions, which may be defined, for example, by computer simulation. There are numerous possible random patterns of planting points, and it would therefore be difficult to decide which pattern is most suitable. Furthermore, and more importantly, the practical implementation of a random design would be very difficult. A planting operation requires clearly defined planting points. Simple and regular patterns are therefore preferred in practice, while a completely random design is likely to be unacceptable. A compromise pattern between the two extremes, completely random and completely regular, may be acceptable by management and at the same time satisfy the demands of silviculture that aims to mimic the patterns observed in natural forests. Accordingly, the objective of this study is to analyze the spatial patterns in different natural forests and, if possible, to identify common structures. Based on that analysis, we will attempt to develop near-natural planting patterns for plantation forests that contain at least 50\% random structural units (as found in all natural forests studied) and as much regularity as possible.

\section{Methods}

\section{Structural units and the uniform angle index}

The spatial structure of a forest may be described using the uniform angle index, which has been applied in numerous studies (Pommerening 2002; Aguirre et al. 2003; Li et al. 2012, 2014; Zhao et al. 2014). We use this method to describe local and small-scale forest structure, which describes the degree of spatial uniformity of the $\mathrm{n}$ nearest neighbors of a given reference tree (Hui and Gadow 2002; Aguirre et al. 2003). Figure 1 shows a structural unit of five trees. A five-tree structural unit is the best compromise between sampling accuracy and costs for practical forest management (Wang et al. 2016; Zhang and Hui 2017). Each tree in a forest with $\mathrm{N}$ trees can be a reference tree, and then there are $\mathrm{N}$ structural units in a forest. Coordinates of points or trees are used to calculate the $W_{i}$ value of the uniform angle index. Two adjacent neighbors and the reference tree $(i)$ form an angle $\left(\alpha_{i j}\right)$. To describe the unit's structure, we measure the smallest angles $\left(\alpha_{i j}\right)$ between 4 pairs of neighbors of the reference tree $(i)$ and compare these values with a standard angle $\left(\alpha_{0}\right)$, which in the case of four neighbors has been found to be equal to $72^{\circ}$ (Hui and Gadow 2002). $W_{i}$ is then defined as the proportion of the number of $\alpha_{i j}$ that are smaller than the standard angle $\left(\alpha_{0}\right)$ of 


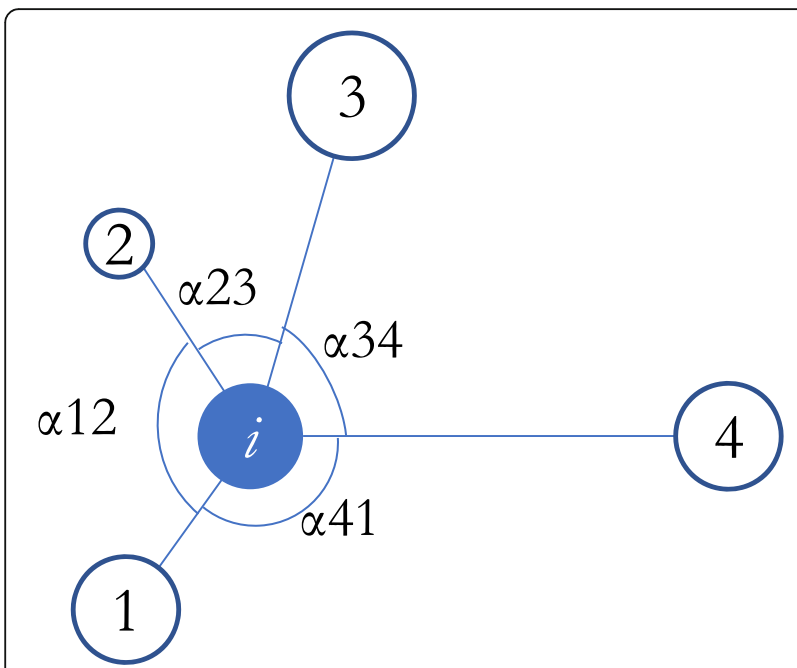

Fig. 1 Schematic diagram of a reference tree (i) with four neighbors and four angles between neighbors

the total number of angles (Hui et al. 1999; Pommerening 2002; Aguirre et al. 2003), as follows:

$$
\begin{aligned}
W_{i} & =\frac{1}{n} \sum_{j=1}^{n} z_{i j}, \text { where } z_{i j} \\
& =\left\{\begin{array}{c}
1, \text { if } \alpha_{i j} \text { angle is smaller than } \alpha_{0} \\
0, \text { otherwise }
\end{array} \text { and } 0 \leq W_{i} \leq 1\right.
\end{aligned}
$$

Different $W_{i}$ values indicate different spatial patterns within a given structural unit. With four neighbors, there are five possible values that $W_{i}$ can assume. Figure 2 shows examples of the five possible $W_{i}$ values and the associated five semantic expressions. The $W_{i}$ values fall in the interval $[0,1]$. The closer a value is to 0 , the more the distribution pattern tends to be regular. On the other hand, when values approach 1 , the distribution pattern tends to be clumped. When $W_{i}=0$, angles between two adjacent neighbors are greater than $\alpha_{0}$, the distribution of four neighbors are independent from each other; when $W_{i}=0.25$, only one smaller angle, the other neighbors are independent. Both of structural units are classified as "regular" ("very even" and "even"). When $W_{i}=0.75$, three angles are less than $\alpha_{0}$ with three neighbors are cluster; when $W_{i}=1$, all the neighbors are aggregated. Both of structural units are classified as "clumped" ("irregular" and "very irregular"). When $W_{i}=0.5$, two angles are less than $\alpha_{0}$ while the other two are greater. This type of structural unit is classified as "random". Because of the higher spatial resolution, this approach allows much greater flexibility in analyzing large forest areas. Instead of classifying a forest spatial pattern using one general label such as "random" or "regular", it is possible to present distributions of structural unit attributes with proportions of regular, random or clumped local patterns (Hui and Gadow 2002; Gadow and Hui 2003). The frequencies of these five possible patterns in a forest reveal much more than a simple classification of the forest as a whole (Hui et al. 2016). It is often advisable to study the distribution of the $W_{i^{-}}$ values, which reveals the structural variability in a given forest. These attributes always refer to a particular reference tree. An additional advantage of this approach, in addition to the higher spatial resolution, is the possibility of selecting reference trees with particular attributes (all trees of a particular species or of a particular dimension) and studying the spatial structure in the vicinity of such trees.

$\bar{W}$ is the mean value of $W_{i}$, which also reflects the overall distribution pattern of a species or stand (Gadow et al. 2003; Hui et al. 2004). Based on the work by Hui and Gadow (2002), forest spatial distributions can be characterized as random $(\bar{W} \in[0.475,0.517])$, even $(\bar{W}$ $<0.475)$ or clumped $(\bar{W}>0.517)$.

\section{Spatial patterns in natural forests}

As mentioned before, we assume that a natural ecosystem can serve as a reference for a planted forest on the same site. Without human intervention, a planted forest must eventually develop the characteristics of its local reference after a very long time. This

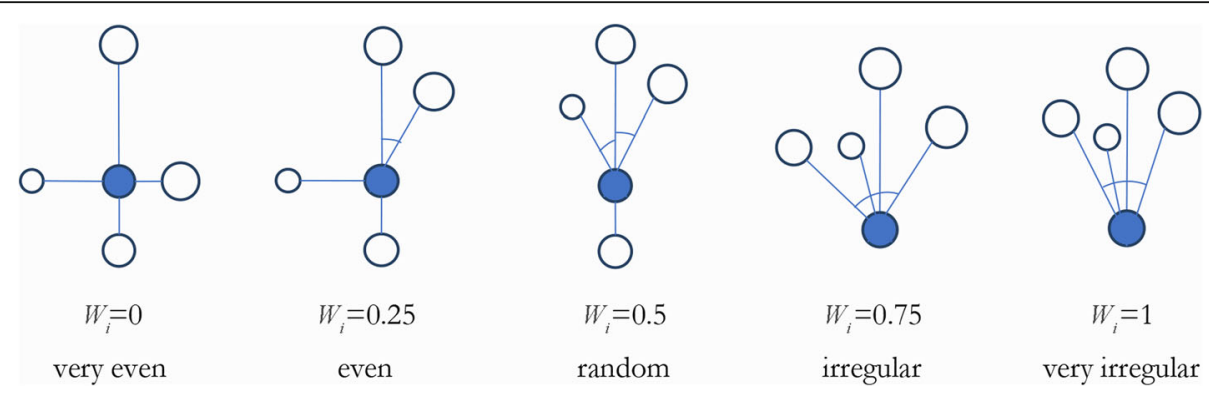

Fig. 2 Details of different $W_{i}$ values and associated semantic descriptors 
assumed natural transformation, which may take a long time, may be reduced by appropriate human intervention, such as designing a planting pattern that resembles natural forest structures without loss of operational convenience. Improving the spatial structure of existing planted forests by human intermediate operations or management is also another way to achieve the goal.

With this objective in mind, we studied the $W_{i}$ distributions of observational plots with mapped trees in six natural forests. None of these natural forests had been subject to silvicultural manipulation or human intervention in recent decades. The six natural forest plots are distributed throughout five different regions in China, and we expect to identify some common structural characteristics that can help us design more "natural" planting patterns for even-aged plantations.

All live trees with a DBH (diameter at breast height) > $5 \mathrm{~cm}$ were tagged, and their positions were mapped with a Topcon GTS602 (Topcon Corporation, Tokyo, Japan) autofocus total station. Tree DBH, height, and crown diameter were measured. Table 2 provides general information on the plots

Plot A was established in 2016, is located in the southern part of a sandy area in Honghuaerji within the Inner Mongolian Autonomous Region. This area belongs to the transitional zone between the eastern slope of the middle of the Daxingan Mountains and the Inner Mongolian plateau $\left(47^{\circ} 36^{\prime}-48^{\circ} 35^{\prime} \mathrm{N}, 118^{\circ}\right.$ $58^{\prime}-120^{\circ} 32^{\prime} \mathrm{E}$ ) at 700 to $1100 \mathrm{~m}$ above sea level. The zone experiences a mid-temperate, semihumid, and semiarid continental monsoon climate, with a mean annual temperature of $1.5^{\circ} \mathrm{C}$ and an average annual precipitation of $344 \mathrm{~mm}$. The main soil type is sand (Liu et al. 2009; Liu et al. 2016). The forest type is Pinus sylvestris var. mongolica, natural pure forests.

Plot B was established in 2010, is located in the Xitian Mountain National Nature Reserve in Gongliu County, Xinjiang Province. This area is part of the Tianshan Mountains $\left(43^{\circ} 59^{\prime}-43^{\circ} 28^{\prime} \mathrm{N}, 87^{\circ} 12^{\prime}-87^{\circ} 50^{\prime} \mathrm{E}\right)$ ranging from 1635 to $1706 \mathrm{~m}$ above sea level. The region experiences a temperate continental climate with mostly cold weather and great changes in temperature. The mean annual temperature is approximately $5{ }^{\circ} \mathrm{C}$ to $7{ }^{\circ} \mathrm{C}$, with an average annual precipitation of 600 to $800 \mathrm{~mm}$. The main soil type is mountain gray cinnamon forest soil, and the forest type is a Picea schrenkiana natural forest with very few Betula tianschanica (Zang et al. 2011).

Plots C and D were established in 2002, are located on an eastern slope of the Jiaohe Forest Experimental Zone Management Bureau in Jilin Province (43.51'$\left.44^{\circ} 05^{\prime} \mathrm{N}, 127^{\circ} 35^{\prime}-127^{\circ} 51^{\prime} \mathrm{E}\right)$, are approximately 400 to $500 \mathrm{~m}$ above sea level. This region experiences a temperate continental monsoon climate, with a mean annual temperature of approximately $3.5^{\circ} \mathrm{C}$ and an average annual precipitation of 700 to $800 \mathrm{~mm}$. The soil type is dark brown soil with high fertility, and the forest type is Pinus koraiensis mixed broadleafconifer composed primarily of coniferous trees such as Pinus koraiensis Sieb. et Zucc and Abies holophylla Maxim. and broadleaf trees such as Fraxinus mandshurica Rupr., Juglans mandshurica Maxim., Acer mandshurica Maxim., Carpinus cordata, Tilia mandschurica Rupr. et Maxim., and Quercus mongolica Fisch.

Plot E was established in 2008, is located within the Xiaolong Mountains in Gansu Province $\left(33^{\circ} 30^{\prime}-34^{\circ}\right.$ $\left.49^{\prime} \mathrm{N}, 104^{\circ} 22^{\prime}-106^{\circ} 43^{\prime} \mathrm{E}\right)$. This area belongs to a warm temperate and north subtropical transitional region approximately $1000 \mathrm{~m}$ above sea level. The region has a mean annual temperature of $7{ }^{\circ} \mathrm{C}$ to $12^{\circ} \mathrm{C}$ and an average annual precipitation of 460 to 800 $\mathrm{mm}$. The soil type is humid dark brown mountain soil with a high organic content, and the forest type is pine and oak mixed forest, containing primarily broadleaf trees such as Quercus aliena var. acuteserrata Maxim., Quercus liaotungensis Koidz., Populus davidiana Dode., Toxicodendron vernicifluum F.A. Berkley, Populus purdomii Rehd., Tilia paucicostata Maxim., Carpinus cordata Bl., Crataegus kansuensis Wils., and Kalopanax septemlobus Koidz. and coniferous trees such as Pinus armandii Franch. and Pinus tabulaeformis Carr.

Plot F was established in 1996, is located within the Jianfengling Nature Reserve in Hainan Province $\left(18^{\circ}\right.$ $23^{\prime}-18^{\circ} 52^{\prime} \mathrm{N}, 108^{\circ} 46^{\prime}-109^{\circ} 02^{\prime} \mathrm{E}$ ) at $800 \mathrm{~m}$ above sea

Table 2 Information details of six natural forest plots. The data was collected in different year (A: 2016; B: 2010; C and D: 2002; E: 2008; F: 1996)

\begin{tabular}{llllll}
\hline Plot & Dimensions & Density $\left(\right.$ trees $\left.\cdot \mathrm{ha}^{-1}\right)$ & Species & Mean DBH $(\mathrm{cm})$ & Basal $_{\left(\mathrm{area}^{-} \mathrm{ha}^{-1}\right)}$ \\
\hline A & $100 \mathrm{~m} \times 100 \mathrm{~m}$ & 924 & 1 & 20.0 & 32.90 \\
B & $200 \mathrm{~m} \times 200 \mathrm{~m}$ & 202 & 3 & 49.4 & 49.27 \\
C & $100 \mathrm{~m} \times 100 \mathrm{~m}$ & 936 & 19 & 16.4 & 28.74 \\
D & $100 \mathrm{~m} \times 100 \mathrm{~m}$ & 1178 & 20 & 14.7 & 30.73 \\
E & $140 \mathrm{~m} \times 70 \mathrm{~m}$ & 888 & 49 & 16.1 & 26.53 \\
F & $100 \mathrm{~m} \times 30 \mathrm{~m}$ & 820 & 85 & 23.5 & 54.87 \\
\hline
\end{tabular}




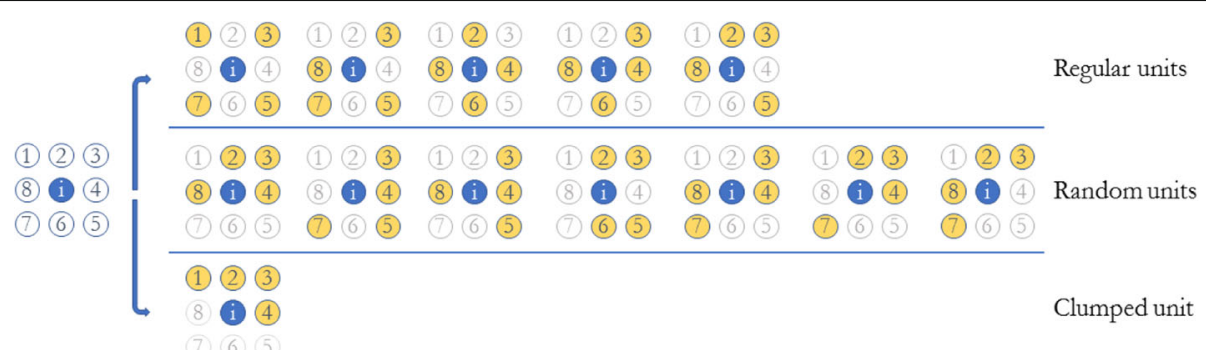

Fig. 3 All possible planting patterns for a structural unit of nine trees: a reference tree in the center that is surrounded by 8 neighbors. With four neighbors, there are 13 different patterns: five even or very even units $\left(W_{i}<0.5\right)$, seven random units $\left(W_{i}=0.5\right)$ and one irregular or very irregular unit $\left(W_{i}>0.5\right)$

level. This area belongs to a tropical monsoon climate (Zhang et al. 1993). The region has a mean annual temperature of approximately $23^{\circ} \mathrm{C}$ and an average annual precipitation of approximately $1150 \mathrm{~mm}$. The soil type is lateritic yellow soil, and the forest type is tropical montane rainforest with high species diversity. Untypical dominant populations include Cryptocarya chinensis, Gironniera subaequalis, Mallotus hookeriana and Nephelium lappaceum.

\section{Generating planting point arrangements}

We start with a unit of $3 \times 3$ planting points that includes one reference tree and its 8 nearest neighbors, which are numbered 1 ...8. All possible planting patterns for a structural unit of nine trees are shown in Fig. 3: a reference tree in the center that is surrounded by 8 neighbors. With four neighbors, there are 13 different patterns: five even or very even units $\left(W_{i}<0.5\right)$, seven random units $\left(W_{i}=0.5\right)$ and one irregular or very irregular unit $\left(W_{i}>0.5\right)$.
Figure 3 shows different types of spatial structures in planted forests, but how can they be used to obtain near-natural planting patterns in an open space with rows and rows of planting points? Imagine all the planting points are empty without trees at the beginning. Three steps are needed to generate planting patterns using $\mathrm{R}$ (Version 3.5.1 https://www.rproject.org/). Step 1) identify a planting point as the first reference tree that is not located at the outer margin of the plot. For that reference tree, there are 8 nearest empty planting point neighbors around it. Step 2) the code will find 4 of 8 points to build a random structural unit and "plant" trees on them; the remaining 4 planting points are empty and will be "destroyed". Now, the first $3 \times 3$ planting points are filled with a random structural unit. Seven possible different random structural units that as could be used Fig. 3 middle row. Step 3) the code moves to the next planting point if it was not "destroyed" in step 2. There are also 8 nearest planting point

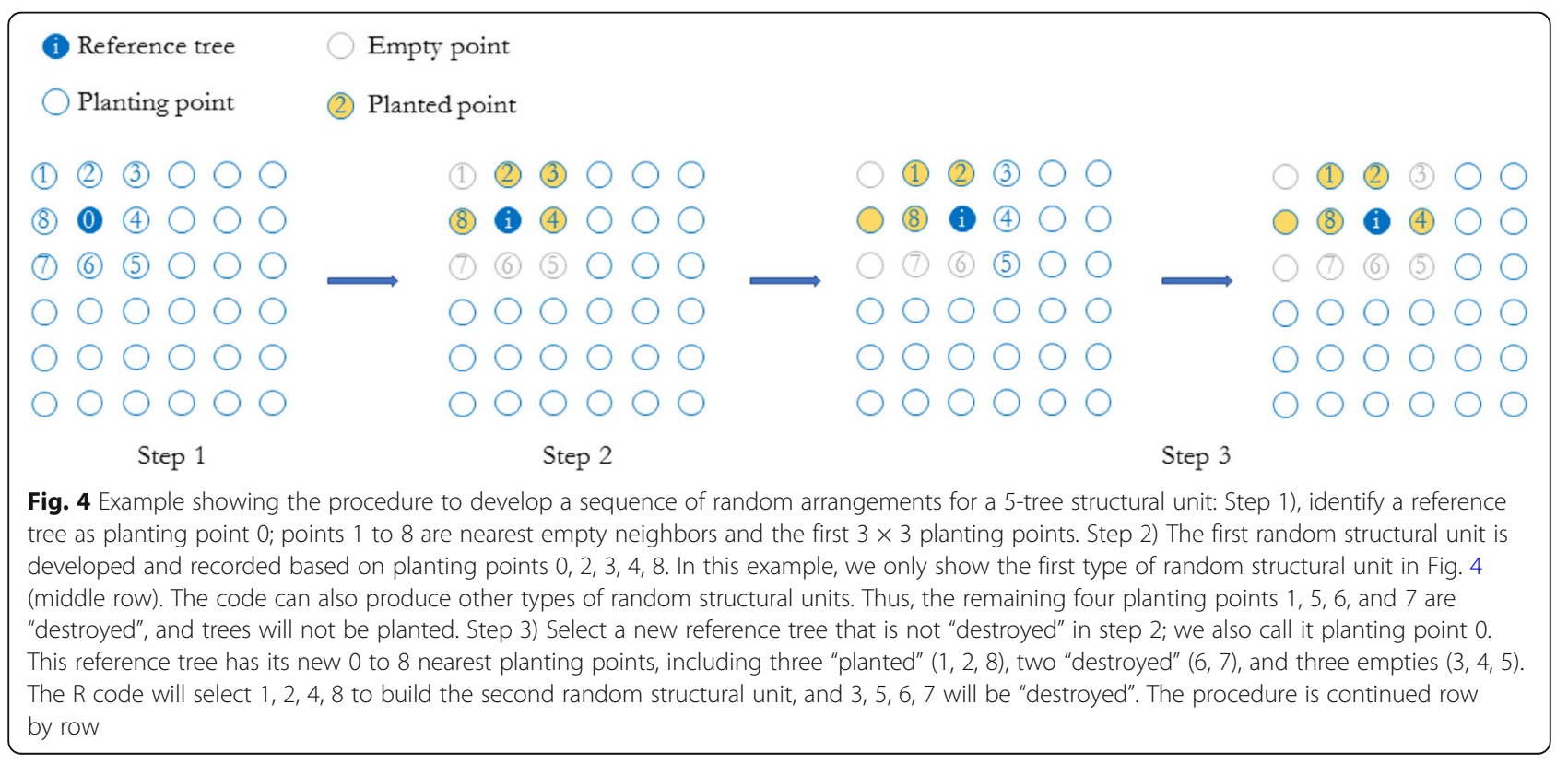


neighbors around it, including some "planted" points and some "destroyed" points. The code will build a second random structural unit with "planted" points and other empty points but will ignore the "destroyed" points in these $3 \times 3$ planting points. Seven possible different random structural units can be chosen as well. The procedure is continued row by row until there are no planting points left in the ground. Figure 4 shows an example to generate a planting pattern.

There are some special situations cases within the algorithm that should be explained: (1) sometimes the next point is already "destroyed" in step 2 or step 3 , in which case the code will pass over this point and go to the next one; (2) a tree cannot be a reference tree if there are not enough trees or empty points to create a unit around it, in which case the code will not choose this tree as a reference tree and go to the next one; (3) a tree cannot be a reference tree if more than four neighbors have been assigned, in which case the code will pass over this point and go to the next one; (4) the code will give priority to establish a random structural unit when a reference tree is found. The $\mathrm{R}$ code in this study is used only as an algorithm and a tool to obtain near-natural planting patterns, but there is no need to run this code when using the planting patterns. The following shows a pseudocode outline using the first type of random structural unit as an example. It starts from any empty planting point 0 in a simulated area.

\section{Optimizing the arrangement of planting points}

We refer to a full allocation if a plantation is established in a regular pattern with one tree on every planting point. Currently, most plantations are established in this way, resulting in a rigid regular pattern with all $W_{i}$ values equal to 0 . We simulated all possible arrangements based on the following objective function:

$$
\max N_{W_{i}=0.5}
$$

with constraints:

(1) $N_{W_{i}=0.5} \geq 0.5 N$;

(2) $N \geq 0.5 N_{0}$;

(3) Regular.

$N_{W_{i}=0.5}$ refers to the number of random units, $N_{0}$ to the number of planting points. For example, $N_{0}$ equals 10 , 000 if the distance between and within rows is $1 \mathrm{~m} \times 1 \mathrm{~m}$ within one hectare. The first constraint could ensure a minimum proportion of random units (as in a natural forest); the second constraint ensures that the planting pattern has a reasonable density to prevent the formation of too many gaps; and the third constraint requires that new arrangements are regular, easy and feasible when producing plantations by using them. To avoid systematic errors resulting from trees near the forest edge, we set a $1 \mathrm{~m}$ buffer on the plot perimeter. The trees in the buffer were calculated as potential neighbors only.

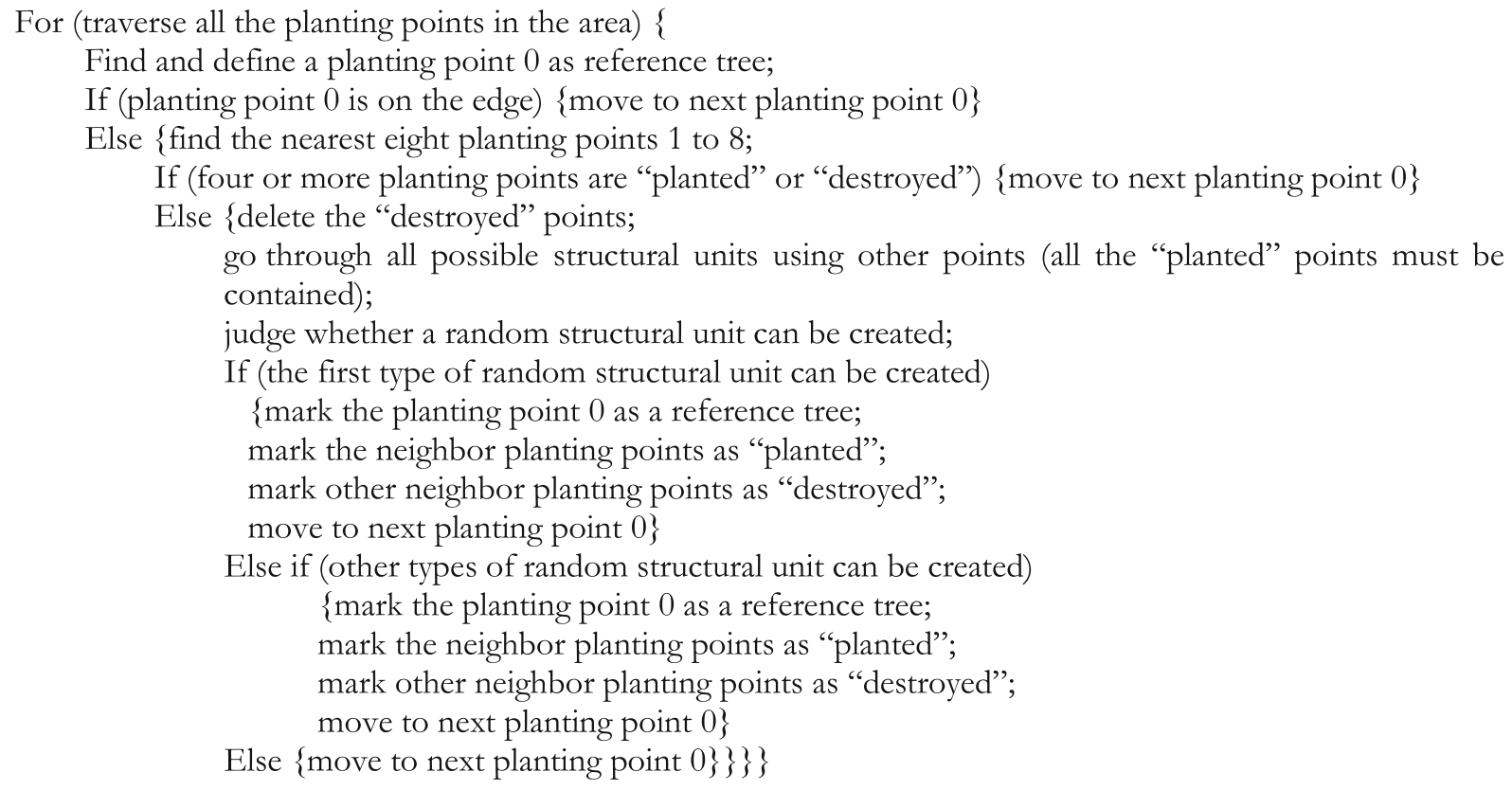


Table 3 Average $\bar{W}$ and associated distribution pattern of the sample plots

\begin{tabular}{lllllll}
\hline Plot & A & B & C & D & E & F \\
\hline $\bar{W}$ & 0.461 & 0.503 & 0.497 & 0.532 & 0.511 & 0.541 \\
Distribution & Even & Random & Random & Cluster & Random & Cluster
\end{tabular}

\section{Results}

\section{Distributions of $W_{i}$ in natural forests}

According to Hui and Gadow (2002), $\bar{W}$ value can be used to judge the overall spatial patterns of forests, see Table 3. Plot A shows an even structure, plot B, C and E present random structure, plot $\mathrm{D}$ and $\mathrm{F}$ are clustered. Although they present different spatial patterns, they have a similar normal distribution of $W_{i}$. Random trees have an absolute advantage, reaching more $50 \%$ in six plots, see Fig. 5. The proportions of even trees and irregular trees are about the same with 10 to $30 \%$. The proportions of very even trees and very irregular trees are the least, are less than $5 \%$.

\section{The five optimum arrangements}

Five different planting point arrangements were obtained where the proportion of random units exceeded 50\% (Fig. 6). The five patterns share several important features: (1) each pattern has fewer plants than the full allocation; (2) the arrangement of planting lines and rows is regular (operational convenience); (3) at least $50 \%$ of structural units are random; the remaining units are either regular or cluster units. This shows a similar result with previous studies (Zhang et al. 2018).

The five arrangements are feasible because they comply with the constraints defined in the methods section. Each pattern has specific characteristics:

- Pattern 1: the first line of the planting points is fully occupied. The following two lines have only one planting point occupied and two vacant points before and after the occupied position in the same line;

- Pattern 2: the first two lines are occupied by two trees, followed by one vacant point; the third line has one tree in every third position;

- Pattern 3: the first line of the planting points is fully occupied, the following line has two occupied planting positions followed by one vacant point, and the third line has no trees;

- Pattern 4: in the first line, all the planting points are fully occupied. The following line has only one tree in every third position;

- Pattern 5: the first line of the planting points has one position occupied, which is followed by three vacant points; the second line is fully occupied; the third line has one planted tree in the third position followed by three vacant points; the fourth and the sixth lines are a repeat of the second line, while the fifth is a repeat of the first line.

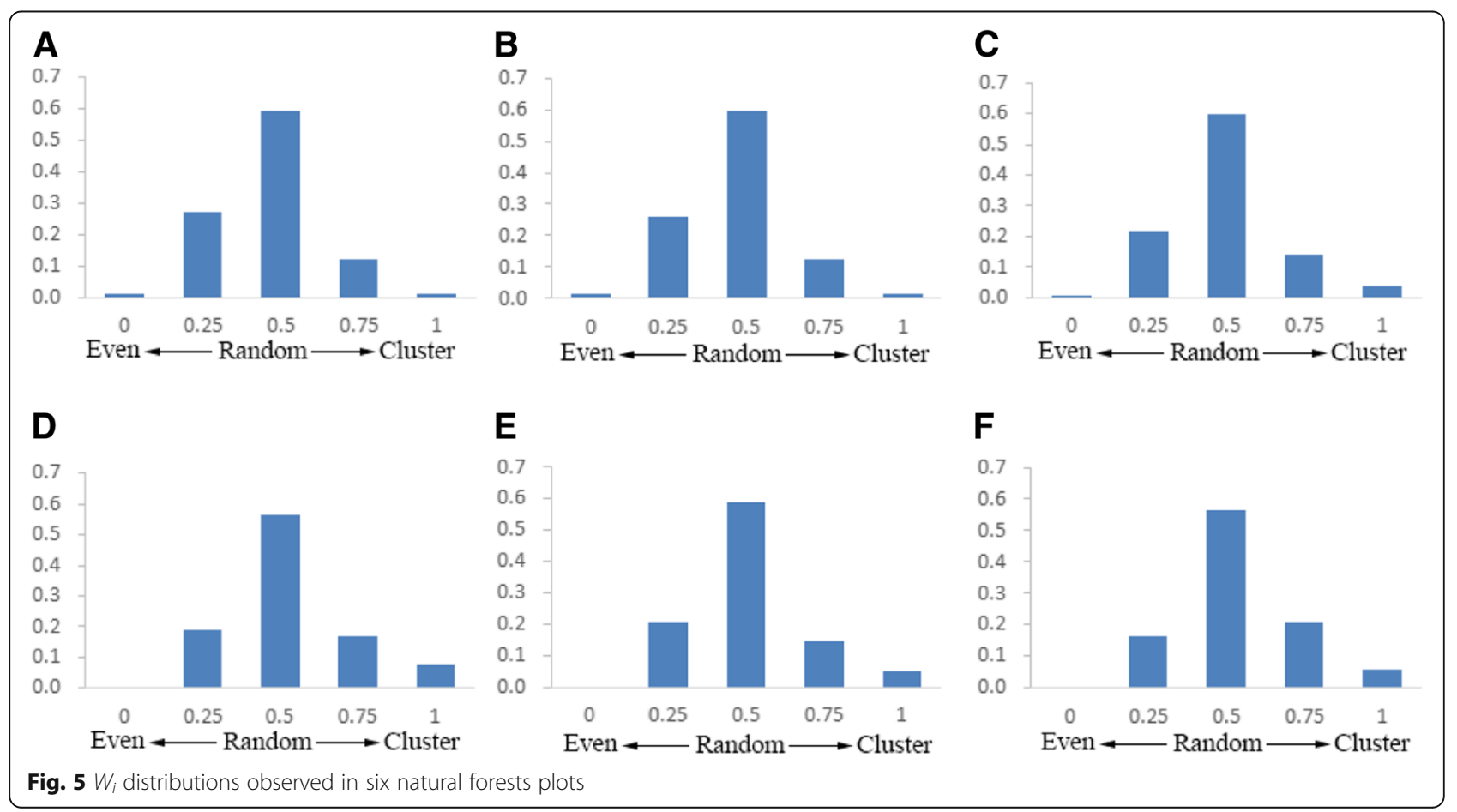




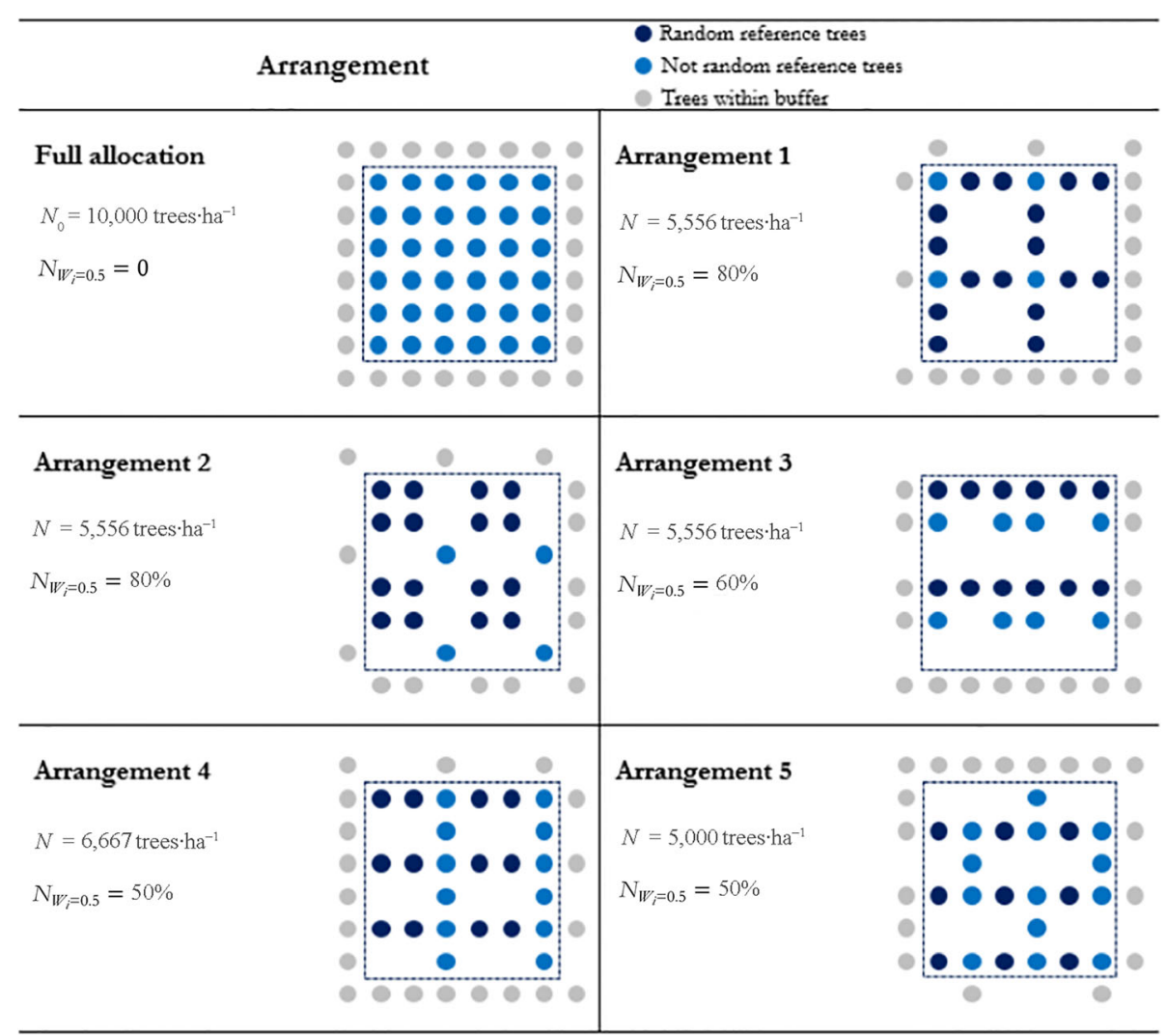

Fig. 6 Five near-natural arrangements with a proportion of random units and density; this figure shows smaller plantations with $8 \times 8=64$ planting points

Patterns 1-4 can be replicated easily for large areas. In pattern 5 , the first 4 lines are replicated. The number of planted trees $(N)$ for these 5 near-natural arrangements is $50 \%-70 \%$ of the full allocation. The proportion of random units has increased considerably to between 50 and $80 \%$ of all units. At $80 \%$, patterns 1 and 2 have the highest proportion of random units: four out of 5 trees are located within a small-scale random environment.

\section{Discussion}

As stated earlier, a forest ecosystem is not only influenced by the competition between trees, but also by the ecosystem dynamics. Before canopy closure, there is no asymmetric competition when trees do not interact with each other, and individuals can fully occupy their surrounding resources, such as plantations in short rotation period. Such cases does not help to study the relationship of spatial structure and the forest ecosystem. Thus, we study stands with connected or overlapping canopies. As age increases, plantations became more complex, because of the diversity of plantation depends largely on the age. For instance, plantations established at the end of the nineteenth century in the Mediterranean region, the primary purpose of which was mainly to recover the vegetation for soil and water conservation due to overgrazing. While after several years' thinning and harvesting, mixed forests of coniferous and broad-leaved have been recovered naturally and its structure and species composition resembled that of the forest before the degradation (Führer 2000). However, to achieve this result, the stands have to go through a long process of natural interference and management. At this point, the research on accelerating the change of plantation forest pattern distribution becomes particularly important, which is also the biggest benefit brought by this research, that is, after stand canopy closure, the new pattern distribution can induce the occurrence of asymmetric competition in a faster manner and make it become near natural forest in a shorter period. It is undeniable that the effect produced by this asymmetric spatial pattern has different intensity and influence in different life cycles of plantation forests. If plantation conducts short-term rotation before the canopy closure, this method is not recommended.

The new approach works in two ways. (1) afforestation. When new plantation forest is established, the above pattern is applied. This requires fewer trees to be planted, less labor and less cost to grow the seedlings, and once the canopy comes into contact, asymmetric competition begins. The whole process does not need 
intermediate operation and management. Thinning can be done in the same pattern when harvesting or crop rotation is required. For example, the plantation with a specific pattern of $1 \times 1 \mathrm{~m}$ interval is thinned into a plantation with the same pattern of $2 \mathrm{~m} \times 2 \mathrm{~m}$, and then the forest continues to grow with canopy closure and generate new asymmetric competition. (2) existing plantation. Existing even plantations are thinned to form the random distribution. The advantage of this method is that it does not require replantation, and the effect of this pattern will gradually emerge during subsequent growth, especially after canopy closure. The downside is that not all plantations are evenly distributed. Even in that case, it is still recommended that the distribution of trees to be managed in a more random way in the process of rotation. Both methods have now been successfully applied in China's plantation forests.

\section{Variable competition}

Traditional planting points for plantations always appear as symmetric arrangements, which may be convenient for carrying out mechanized operations. These ideas are inherent in planting policies that call for regular spacings and thinning operations that aim to leave an evenly stocked stand (Stiell 1978). However, compared to natural forests with a more complex structure and richer diversity, plantations may face a series of problems, including low diversity and higher biotic risks: "Current individual tree growth models rarely consider the specific kind of intertree competition, which can be sizeasymmetric when growth is limited by light or sizesymmetric when belowground resources are scarce" (Pretzsch and Biber 2010). Edge effects may explain this phenomenon. The forest edge usually provides a different environment, which is often more favorable for individual trees, when compared with the inside where the trees are completely surrounded by neighbors (Xiao et al. 2003; Wuyts et al. 2008). It is evident that clumped trees experienced an overall reduction in the quantity of foliage in comparison with single trees, resulting in lower DBH growth (Stiell 1978).

The five optimum patterns will have the effect that competition will vary for each individual position. This variability in the community more closely resembles natural communities than a regular pattern where all trees are subject to the same competition effects. This variability may result in greater resilience of the community, but this assumption must be tested with empirical evidence. For this reason, the theoretical planting patterns developed in this study are already being used in experimental plantings of Pinus tabulaeformis plantations in Tianshui in Gansu Province (Fig. 7) and in a Populus deltoides plantation in Fangshan near Beijing.

\section{Effect of changing basic espacements}

Our results are based on a hypothetical $1 \mathrm{~m} \times 1 \mathrm{~m}$ espacement with 10,000 trees per hectare. If the distance between and within rows changes, e.g., to $0.5 \mathrm{~m} \times 0.5 \mathrm{~m}, 2$ $\mathrm{m} \times 2 \mathrm{~m}$ or $5 \mathrm{~m} \times 5 \mathrm{~m}$, then the tree density will change, but not the pattern. Structural units that are characterized by the uniform angle index are not modified by the distance of the neighbors, only by the angles between neighboring trees (Hui and Gadow 2002; Aguirre et al. 2003; Li et al. 2012, 2014). The new planting patterns can be chosen while changing the initial espacements of individuals. It is therefore possible to establish a plantation with different espacements and different numbers of trees per ha, using any one the five optimum patterns.

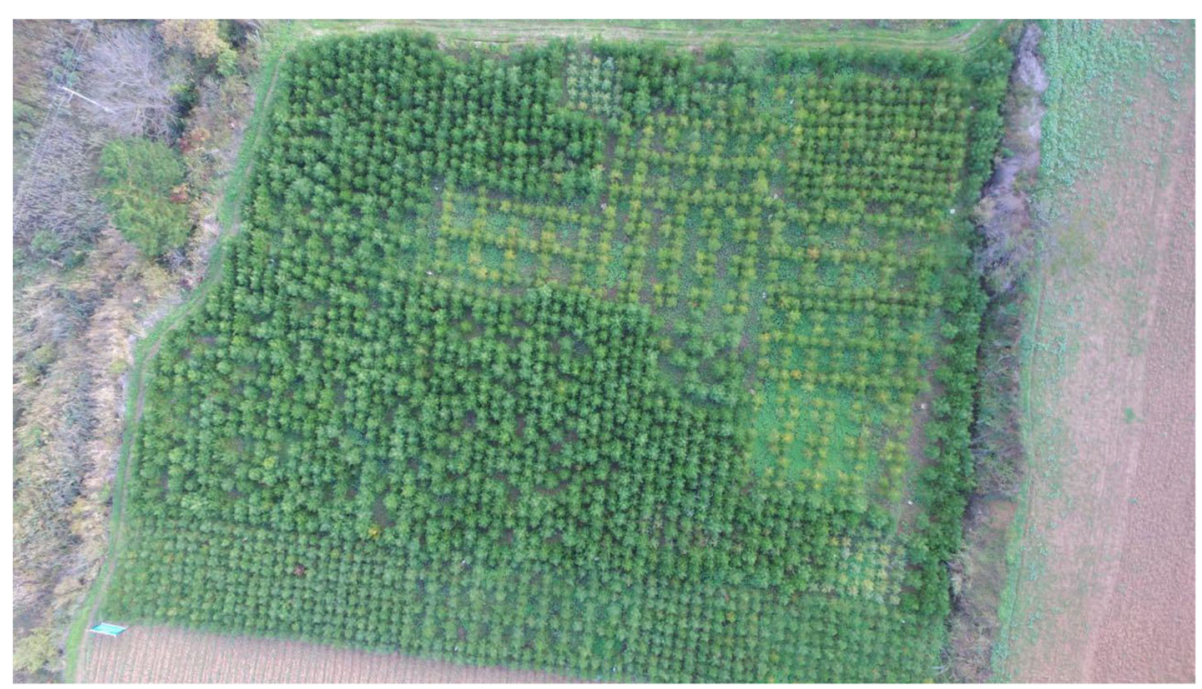

Fig. 7 Pinus tabulaeformis plantations in Tianshui in Gansu Province, China 


\section{Empty planting points}

Each of the five optimum patterns has empty spaces, i.e., planting points that are not occupied. These exposed gaps are likely to develop naturally, for example, by specific herbaceous plant communities or invading pioneering tree species if the plantation is located in the vicinity of a natural forest. Such invading natural regeneration is usually seen as undesirable in a planted forest and is eliminated. However, these invasions may also have positive effects by initiating the development of near-natural forest communities (Emborg and Heilmannclausen 2000; Lu et al. 2006; Larsen and Nielsen 2007).

Agroforestry is another way to use the gaps before the canopy closure of the plantation. Increasingly, agroforestry is viewed as providing ecosystem services, environmental benefits, and economic commodities as part of a multifunctional working landscape. The multifunctional role of agroecosystems has been emphasized by both the Millennium Ecosystem Assessment (2005) and the International Assessment of Agricultural Science and Technology for Development (2008). China has much experience with agroforestry. More than 150 tree species, especially Pinus massoniana and Populus, are planted in different regions of China in association with agricultural crops (Fang et al. 2005; Cheng et al. 2010). A wide range of agroforestry management systems involving Cunninghamia lanceolate has also been applied in China. The use of gaps in the optimum patterns may thus create new opportunities for agroforestry crop production (Guo 2014).

\section{Conclusion}

This study identified common structural characteristics observed in six natural forests in different regions of China. Any arbitrary regular arrangement of planting points exhibits 13 structural units, of which seven are random, five are even and one is clustered. Based on this pattern, we developed an objective function with constraints, simulated the planting points for plantations and finally found 5 optimum arrangements with an increased proportion of random units. Among the five optimum arrangements, patterns 1,2 and 3 have the same planting density (5556 trees.ha ${ }^{-1}$ ). It appears that the first two arrangements may be preferable when a high proportion of random units is required. Patterns four and five have the same proportion of random units (50\%). However, pattern four has more trees (6667 tree$\mathrm{s} \cdot \mathrm{ha}^{-1}$ ) than pattern five (5000 trees.ha ${ }^{-1}$ ), and this pattern is preferable when high planting densities are preferred.

\section{Abbreviations}

$\bar{W}$ : Mean value of $W_{i}$ of a forest; $\mathrm{DBH}$ : Diameter at breast height (outside bark at $1.3 \mathrm{~m}$ above ground): $W_{i}$ : Uniform angle index value for a given reference tree $i$

\section{Acknowledgements}

We gratefully acknowledge Liu Wenzhen and Ma Jianwei from the Xiaolongshan Research Institute of Forestry of Gansu Province, who participated in the investigation in Gansu Province. We would like to thank all of the reviewers and editors for reading the manuscript and providing useful feedback.

\section{Funding}

This work was supported by the National Key Research and Development Program of China (2016YFD0600203); this funding is gratefully acknowledged.

\section{Availability of data and materials \\ The datasets used and/or analyzed during the current study are available from the corresponding author upon reasonable request.}

\section{Authors' contributions}

ZG and HG drafted the manuscript, ZG drew the figures, KvG modified the manuscript, and all authors contributed to the writing of the manuscript. All authors read and approved the final manuscript.

Ethics approval and consent to participate

Not applicable.

Consent for publication

Not applicable.

\section{Competing interests}

The authors declare that they have no competing interests.

\section{Author details}

'Research Institution of Forestry, Chinese Academy of Forestry, Beijing 100091, China. ${ }^{2}$ Chinese Society of Forestry, Beijing 100091, China. ${ }^{3}$ University of Göttingen, Göttingen, Germany.

Received: 27 July 2018 Accepted: 16 May 2019

Published online: 29 May 2019

\section{References}

Aguirre O, Hui GY, Gadow KV, Pérez JJ (2003) An analysis of spatial forest structure using neighbourhood-based variables. For Eco Manage 183(1):137145

Allen RB, Platt KH, Coker REJ (1995) Understory species composition patterns in a Pinus radiata D. Don plantation on the central North Island volcanic plateau. NZ J Forest Sci 25:301-317

Baker FS (1934) Theory and practice of silviculture, 2nd edn. McGraw-Hill Book Co. Inc, New York and London

Bartelink HH, Olsthoorn AFM (1999) Introduction: mixed forest in western Europe. Ibn Scientific Contributions

Bauhus J, Puettmann KJ, Kühne C (2013) Close-to-nature forest management in Europe: does it support complexity and adaptability of forest ecosystems? In: Messier C, Puettmann KJ, Coates KD (eds) Managing forests as complex adaptive systems: building resilience to the challenge of global change. Routledge, New York

Bella IE (1967) Development of jack pine and Scots pine in the Spruce Woods Forest Reserve. Manitoba. Government of Canada, Department of Forestry and Rural Development, Forest Research Laboratory, Winnipeg, Departmental Publication

Bormann FH, Likens GE (1979) Pattern and process in a forested ecosystem. Springer, New York

Breugel MV, Bongers F, Mart'inez-Ramos M (2007) Species dynamics during early secondary forest succession: recruitment, mortality and species turnover. Biotropica 39(5):610-619

Carnus JM, Parrotta J, Brockerhoff E, Arbez M, Jactel H, Kremer A, Lamb D, O'Hara K, Walters B (2006) Planted forests and biodiversity. J For 104(2):65-77

Chen C, Park T, Wang XH, Piao SL, Xu BD, Chaturvedi RK, Fuchs R, Brovkin V, Ciais P, Fensholt R, Tømmervik H, Bal G, Zhu Z, Nemani RR, Myneni RB (2019) China and India lead in greening of the world through land-use management. Nat Sustain 2:122-129

Chen ZH, Zhang MH, Hou M, Li HX, Wen SL, Yang ZD, Chang MS (2014) Influences of different slope positions and afforestation density on growth of four Eucalyptus (in Chinese). Hubei Agr Sci 53(3):598-600 
Cheng P, Cao FL, Wang GB (2010) The progress of study on agroforestry (in Chinese). J Nanjing Forest Unive (Nat Sci) 34(3):151-156

Christensen M, Emborg J (1996) Biodiversity in natural versus managed forest in Denmark. For Eco and Manage 85:47-51

Condit R, Ashton PS, Baker P, Bunyavejchewin S, Gunatilleke S, Gunatilleke N, Hubbell SP, Foster RB, Itoh A, LaFrankie JV, Lee HS, Losos E, Manokaran N, Sukumar R, Yamakura T (2000) Spatial patterns in the distribution of tropical tree species. Science 288:1414-1418

Connell JH (1971) On the role of natural enemies in preventing competitive exclusion in some marine animals and in rain forest trees. In: Boer PJ, Gradwell GR (eds) Dynamics of Populations. PUDOC, Wageningen, NL, pp. 298-312

Duncan RP (1991) Competition and the coexistence of species in a mixed podocarp stand. J Ecol 79:1073-1084

Dunning D (1923) Some results of cutting in the sierra forests of California. U.S. Dep Agric Bull 1176

Emborg J, Heilmannclausen J (2000) The structural dynamics of Suserup Skov, a near-natural temperate deciduous forest in Denmark. For Eco Manage 126(2): 173-189

Fang S, Xu X, Yu X, Li Z (2005) Poplar in wetland agroforestry: a case study of ecological benefits, site productivity, and economics. Wetlands Eco Manage 13(1):93-104

Führer E (2000) Forest functions, ecosystem stability and management. For Eco Manage 132:29-38

Gadow KV, Hui GY, Chen BW, Albert M (2003) Beziehungen zwischen Winkelmaß und Baumabstaenden. Forstw Cbl 122:127-137

Gonçalves C, Batalha M (2011) Towards testing the "honeycomb rippling model" in cerrado. Braz J Biol 71:401-408

Gunderson L (2000) Ecological resilience: in theory and application. Ann Rev Ecol System 31:425-439

Guo SN (2014) Study on interspecific competition of plant in agroforestry system (in Chinese). Soil Water Conserv Sci Technol Shanxi (2):7-10

Hartley MJ (2002) Rationale and methods for conserving biodiversity in plantation forests. For Eco Manage 155:81-95

He F, Duncan RP (2000) Density-dependent effects on tree survival in an oldgrowth Douglas fir forest. J Ecol 88:676-688

Helms JA (1998) The dictionary of forestry. Society of American Foresters, Bethesda, MD

Holling CS (1973) Resilience and stability of ecosystems. Ann Rev Ecol System 4:1-23

Huang CY, Wu HZ (1990) Study on afforestation density of Cunninghamia (in Chinese). J Fujian Forest Sci Technol 59(1):18-27

Hubbell SP (1979) Tree dispersion, abundance, and diversity in a tropical dry forest. Science 203:1299-1309

Hubbell SP, Ahumada JA, Condit R, Foster RB (2001) Local neighborhood 22 effects on long-term survival of individual trees in a neotropical forest. Ecol Res 16:859-875

Hui GY, Gadow KV (2002) Das Winkelmass - Theoretische Überlegungen zum optimalen Standardwinkel. Allgemeine Forst u. Jagdzeitung 173(9):173-177

Hui GY, Gadow KV, Albert M (1999) The neighbourhood pattern - a new structure parameter for describing distribution of forest tree position (in Chinese). Sci Silvae Sin 35:37-42

Hui GY, Gadow KV, Hu YB, Chen BW (2004) Characterizing forest spatial distribution pattern with the mean value of uniform angle index (in Chinese) Acta Ecol Sin 24:1225-1229

Hui GY, Gadow KV, Zhao ZH, Hu YB, Xu H, Li YF, Zhang LJ, Zhang GQ, Liu WZ, Yuan SY (2016) Principles of structure-based Forest management (in Chinese). China Forestry Publishing House, Beijing

Huston M, Smith T (1987) Plant succession: life history and competition. Am Nat 130:168-198

Jacobsen MK (2001) History and principles of close to nature forest management: a central European perspective. Naconex 3:56-58

Jactel H, Brockerhoff E, Duelli P (2005) A test of the biodiversity-stability theory: Meta-analysis of tree species diversity effects on insect pest infestations, and re-examination of responsible factors 235-262 in Forest diversity and function Temperate and boreal systems Ecological Studies 176, SchererLorenzen M, Ch Körner, Schulze E-D (eds). Springer-Verlag, Berlin and Heidelberg

Janzen DH (1970) Herbivores and the number of tree species in tropical forests. Am Nat 104:501-528

Larsen JB, Nielsen AB (2007) Nature-based forest management--where are we going? Elaborating forest development types in and with practice. For Eco Manage 238(1):107-117
Li YF, Hui GY, Zhao ZH, Hu YB (2012) The bivariate distribution characteristics of spatial structure in natural Korean pine broad-leaved forest. J Veg Sci 23: 1180-1190

Li YF, Hui GY, Zhao ZH, Hu YB, Ye SM (2014) Spatial structural characteristics of three hardwood species in Korean pine broad-leaved forest-validating the bivariate distribution of structural parameters from the point of tree population. For Eco Manage 314:17-25

Lieberman D, Lieberman M (1987) Forest tree growth and dynamics at La Selva, Costa Rica. J Trop Ecol 3:347-358

Liu L, Hu YB, Wang QX, Wang HX, Zhang JL, Wang CL, Zhao ZH (2016) Structure characters of Pinus sylvestris var. mongolica natural forest on sandy land (in Chinese). Forest Res 29(5):623-629

Liu SR, Ma JM, Miao N (2015) Achievements in natural forest protection, ecological restoration, and sustainable management in China (in Chinese). Acta Ecol Sin 35(1):212-218

Liu Y, Bao G, Song HM, Cai QF, Sun JY (2009) Precipitation reconstruction from Hailar pine (Pinus sylvestris var. mongolica) tree rings in the Hailar region, Inner Mongolia, China back to 1865 AD. Palaeogeogr Palaeoclimatol Palaeoecol 282:81-87

Lu YC, Zhang SG, Lei XD (2006) Development of planning system of close-tonature forest management for multiple benefits ecological forestry in China. Proceedings of Sino-German symposium 2006. The sustainable harvest of non - timber Forest products in China: strategies to balance economic benefits and biodiversity conservation. Goettingen, Germany 76-86

Ma J, He CZ, Xie H, Yang Z, Wang F, Yan L (2015) Effects of planting density on the growth of introduced young Populus deltoids forest. For Invent Plan 40(5):88-90

Mason B, Kerr G, Pommerening A, Edwards C, Hale S, Ireland D, Moore R (2003) Continuous cover forestry in British conifer forests. Quart J Forest 2004:38-53

Moravie MA, Audrey R (2003) A model to assess relationships between forest dynamics and spatial structure. J Veg Sci 14:823-834

Nys C (1999) Effet des amendements et fertlisants associe's sur le fonctionnement de l'e'cosyste'meforestier. P. 191-203 in Proc. Congre's GEMAS COMIFER "Raisonner la fertilisation pour les ge'n Dec. 2, 1999, Blois, France, Thevenet G, and Joubert A (eds) Institut National de la Recherche Agronomique, Paris, France

O'Hara KL (1996) Dynamics and stockinglevel relationships of multi-aged ponderosa pine stands. For Sci 42(4):33

Oliver CD, Larson BC (1996) Forest stand dynamics. Wiley

Paquette A, Messier C (2010) The role of plantations in managing the world's forests in the Anthropocene. Front Ecol Environ 8(1):27-34

Parrotta JA, Turnbull JW, Jones N (1997) Catalyzing native forest regeneration on degraded tropical lands. For Eco Manage 99(1-2):1-7

Pautasso M, Holdenrieder O, Sten-Lid J (2005) Susceptibility to fungal pathogens of forests differing in tree diversity P 263-289 in Forest diversity and function Temperate and boreal systems Ecological Studies 176, Scherer-Lorenzen, M, Ch Ko"rner, and E-D Schulze (eds) SpringerVerlag, Berlin and Heidelberg

Pommerening A (2002) Approaches to quantifying forest structures. Forestry 75(3):305-324

Pretzsch H, Biber P (2010) Size-symmetric versus size-asymmetric competition and growth partitioning among trees in forest stands along an ecological gradient in Central Europe. Can J For Res 40(2):370-384

Puettmann KJ, Scott MW, Susan CB, Pablo JD, Lars D, Girma A, Brian DH, Thomas K, Lu YC, Susanna N, Francis EP, Toshiya Y, Jürgen B (2015) Silvicultural alternatives to conventional even-aged forest management - what limits global adoption? For Ecosyst 2:8

Redfearn A, Pimm SL (1987) Insect outbreaks and community structure. In: Barbosa P, Schultz JC (eds) Insect outbreaks. AP, San Diego

Schütz JP (2002) Silvicultural tools to develop irregular and diverse forest structures. Forestry 75:329-337

Schütz JP, Pukkala T, Donoso PJ, Gadow KV (2012) Historical emergence and current application of CCF. In: Pukkala T, Gadow KV (eds) Continuous cover forestry. Springer Verlag, Dordrecht, Heidelberg

Shao QH (2003) An elucidation to nature-approximating forestry and forestry target (in Chinese). World Forest Res 16(6):1-5

Sheng WT (2014) Plantation Forest and their Silvicature Systems in China (in Chinese. Chinese Forestry Publishing House, Beijing

Stiell WM (1978) How uniformity of tree distribution affects stand growth. Forest Chron 54(3):156-158

Tang MP (2003) Study on forest spatial structure analysis and optimal management model (in Chinese). Beijing Forestry University, pp 167 
Toda M, Yokozawa M, Emori S, Hara T (2010) More asymmetric tree competition brings about more evapotranspiration and less runoff from the forest ecosystems: a simulation study. Ecol Model 221:2887-2898

Tourney JW, Korstian CF (1947) Seeding and planting in the practice of forestry, 3rd edn. John Wiley \& Sons, Inc, New York

Valverde T, Silvertown J (1997) Canopy closure rate and forest structure. Ecology 78:1555-1562

Wang HX, Zhang GQ, Hui GY, Li YF, Hu YB, Zhao ZH (2016) The influence of sampling unit size and spatial arrangement patterns on neighborhood-based spatial structure analyses of forest stands. Forest Syst 25(1):e056

Weiner J (1990) Asymmetric competition in plant populations. Trends Ecol Evol 5(11):360-364

Weiner J, Thomas SC (1986) Size variability and competition in plant monocultures. Oikos 47:211-222

Werger MJA, Hirose T, During HJ, Heil GW, Hikosaka K, Ito T, Nachinshonhor UG, Nagamatsu D, Shibasaki K, Takatsuki S, van Rheenen JW, Anten NPR (2010) Light partitioning among species and species replacement in early successional grasslands. J Veg Sci 13(5):615-626

Wuyts K, De SA, Staelens J, Gielis L, Vandenbruwane J, Verheyen K (2008) Comparison of forest edge effects on throughfall deposition in different forest types. Environ Pollut 156(3):854-861

Xiao DN, Li XZ, Gao J, Chang Y, Zhang N, Li ST (2003) Landscape ecology (in Chinese). Science, Beijing

Xiao TC, Han LY, Mo KL (2010) Discussion on the planting technique of Cunninghamia lanceolate (in Chinese). J Sichuan Forest Sci Technol 34(8):109-111

Yang LM (2001) Reviews of the study on the maintaining mechanism of species diversity (in Chinese). J Jilin Agr Univ 23(4):51-55

Yin WL (2015) Advances in the relationship between forest and environment in the world. J Forest Environ 35(1):1-7

Zang RG, Jing XH, Liu H, Liu GF, Ding Y, Cheng KW, Zhang J, Wu XC, Zhang XP, Liu P, Zhang ZD, Wang JP (2011) The ecological characteristics of forest vegetation in northern Xinjiang (in Chinese. Modern Education Press, Beijing

Zeng WS, Tomppo E, Healey SP, Gadow KV (2015) The national forest inventory in China: history - results - international context. Forest Ecosys 2:23

Zhang GQ, Hui GY (2017) Data investigation and analysis method for forest sample - case study of Platycladus orientalis plantation in West Hill of Beijing (in Chinese). Forest Res 30(4):633-639

Zhang GQ, Hui GY, Zhao ZH, Hu YB, Wang HX, Liu WZ, Zang RG (2018) Composition of basal area in natural forests based on the uniform angle index. Ecol Inform 2018:45

Zhang JC, Jiang YX, Wang LL, Huang Q, Zheng DZ, Li YD, Zhao YM (1993) Application of quadrant method in the investigation of tropical montane rainforest (in Chinese). Chin J Plant Ecol 17(3):207-215

Zhao ZZ, Hui GY, Hu YB, Wang HX, Zhang GQ, Gadow KV (2014) Testing the significance of different tree spatial distribution patterns based on the uniform angle index. Can J For Res 44(11):1417-1425

Zhu SG (2014) The research on matching technology of high-yield cultivation for eucalyptus-taking the state owned Weidu Forest farm of Guangxi as example (in Chinese). Central South Univ Forest Technol 3-22

\section{Submit your manuscript to a SpringerOpen ${ }^{\circ}$ journal and benefit from:}

- Convenient online submission

- Rigorous peer review

- Open access: articles freely available online

High visibility within the field

- Retaining the copyright to your article

Submit your next manuscript at $\boldsymbol{\nabla}$ springeropen.com 